\title{
LANGUAGE USED IN ADVERTISEMENTS OF COCO CHANEL PERFUME
}

\author{
Alma Toplana \\ SH.M.P "LasgushPoradeci"
}

\begin{abstract}
Propaganda is an information that is used to influence people by presenting arguments and is present everyday in our lives, this paper shows just a little bit of the influence of propaganda through advertisements how they affect us and what forces us to buy that sort of product.

The topic treated in this paper are adverts of perfume Channel how they represent female gender and how they affect us with those glamorous and expensive adverts making us feel beautiful and feminine. Considering that Chanel is one of the largest company business in the world and the success of being a best seller of course is thanks to good adverts. Creating very qualitative TV adverts, slogans and also quotes about women, making them feel very confident and using powerful women in their adverts in a way they had directly influenced in personality of women that every dream of woman is to show her feminine parts.
\end{abstract}

\section{Introduction}

Fashion designer Coco Chanel, born August 19, 1883, in Saumur, France, is famous for her timeless designs, trademark suits and little black dresses. Chanel was raised in an orphanage and taught to sew. She had a brief career as a singer before opening her first clothes shop in 1910. In the 1920s, she launched her first perfume and eventually introduced the Chanel suit and the little black dress, with an emphasis on making clothes that were more comfortable for women. She died on January 10, 1971.(Biography.com, 2018)

The first appearance of Gabrielle Coco Chanel fragrance was in 1921 and it changed the entire world. The perfume No5 came when she was presented with five fragrances and her choice was number five. Searching more for Chanel she was a girl who owned a shop that sells hats, later she started selling clothes that made a revolution because they were very good quality including trousers and releasing women from tight corsets and "The Little Black Dress" was first essential in a woman wardrobe.

Considering the fact that Coco's perfumes wore great stars like Merlyn Monroe couldn't be better advertisement. Chanel also gives importance quotes, they use powerful quotes in a way every woman can find herself in it, Ex. 


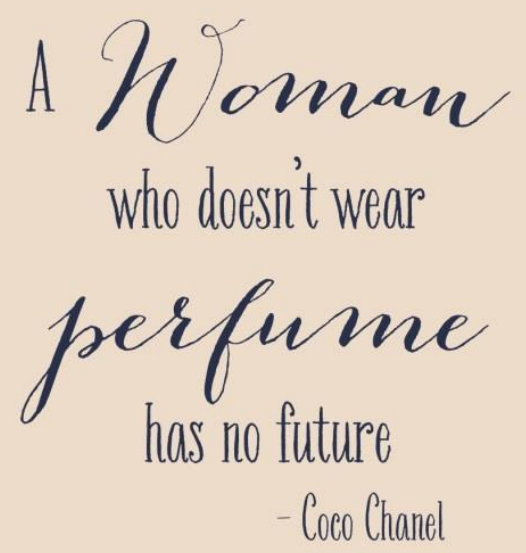

This quote according to women is very powerful because it represents the feminine side of the woman. Considering woman to be very delicate and to know what is good for her also to smell good in a meaning that she is capable doing on her own and the most important, perfume kind of makes you feel more confident and classy. Even me when 1 read this quote more and more it sticks on my mind that if 1 buy this perfume it will change my behavior towards the others, 1 will feel fearless, hopeful and very courageous and this is the purpose of the Chanel adverts through the dominant quotes to achieve till the mind of the woman.

What is important to mention that Chanel always use the well-known figures, models, actresses, singers because they represent in a best way the character of an authoritative, energetic woman and seeing that each of us wants to be like any model or singer that we like of course when we think Chanel we imagine our-self in their place.

Commercial for the new fragrance Gabrielle is very fascinating, with a song by Beyoncé who is considered to be the queen of music nowadays, and with a very attractive and lovely actress Kristen Stewart.She appears very explosive and breathtaking and all the time she is running, and according to Beyoncé's song Running gives the message that she is being herself and of course if you possess the Gabrielle you will immediately think of Kristen running even she is tired she's mesmerizing and beautiful and we put our-self in her place, and this is how propaganda works actually to control our mind through powerful quotes, slogans and commercials. 


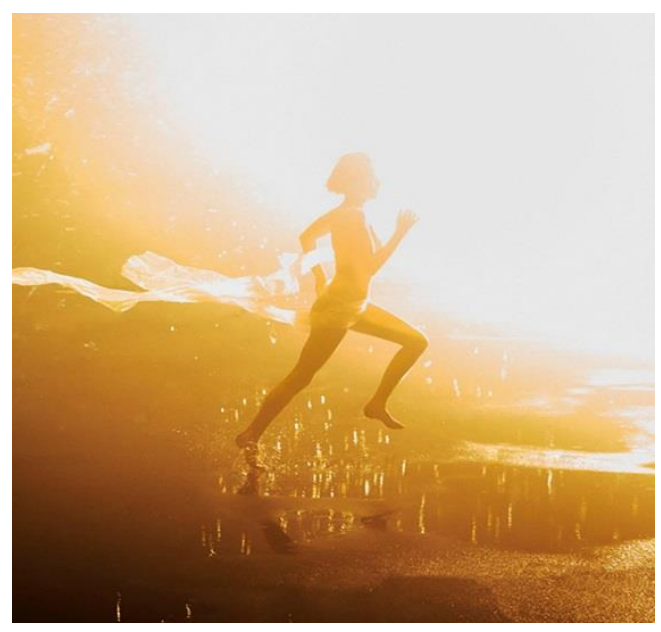

I don't know why women want any of the thing men have, when any of the things women that women have are men

\section{Coco Chanel.}

There is no doubt that Gabrielle know what was she talking about she was very hard-working woman that being independent from a man could stand on her feet and be one of the most famous and influential people in the world. While I was reading the comments in the latest commercial for Gabrielle fragrance most of the comments where how beautiful, stunning and gorgeous was Kristen, that Chanel did a very good job cooperating with her that no-one could act better than her in this short story, and how this commercial in a way forced a lot of persons to want even more this perfume just because Kristen.

Also a great impact has Beyoncé's song because there are few people who don't listen to Beyoncé's songs so Chanel was very well-prepared when decided to put on the market new perfume, because in a way know how to control people minds not only women also men because Chanel has got perfumes for men and always uses powerful personalities which attracts both sexes. 


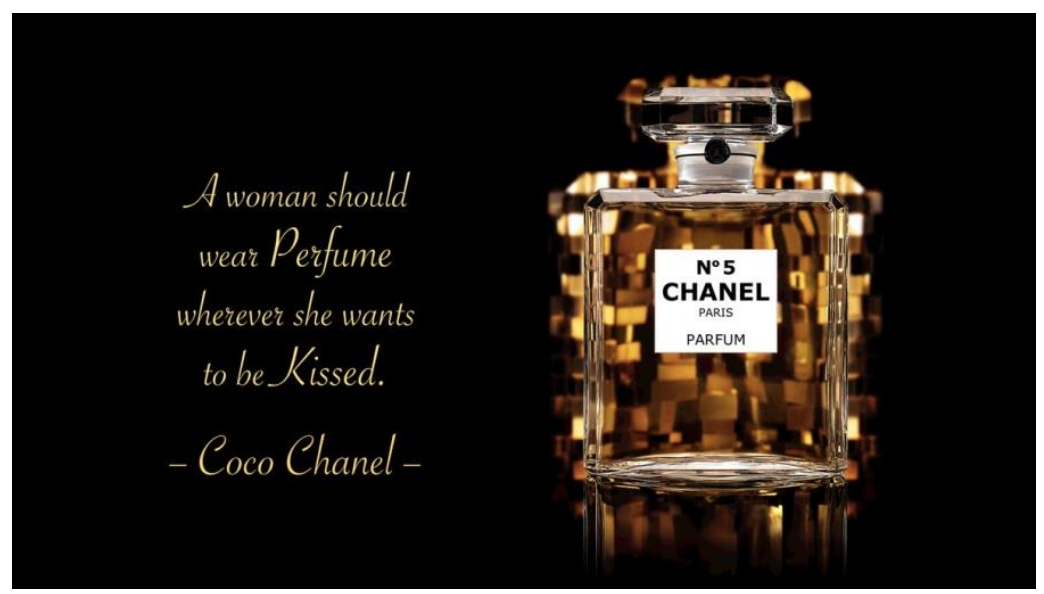

Coco Chanel always pays attention to small details and shows the feminine side of the woman. Black color is dark in a sense of power and the perfume is shown very extravagant with tones of gold in a sense how the women should be treated. Considering that perfume N'5 is one of the most wanted perfumes in the world, while reading feedback most of the buyers wrote that is very sophisticated and old-fashioned, when you put this perfume you feel unique and very classic it is a bit expensive but it's worth the money.

The advert also has the impact that you will have all the attention when you wear this perfume which is mix of orient and spicy and they will make a woman smell like woman in a best way possible.

\section{Conclusion}

I didn't have the chance to try or buy the Chanel's perfume, but while reading an analyzing quotes of Chanel and how did she managed to break the taboo that women shouldn't be seen as an object or just to take care for the house, raise children and always need a man's help or can't express their opinions, but woman too can stand on her feet and do best on her own, she is independent, generous and far more intelligent than men. Reading her quotes, watching commercials in a way it made me feel too like if 1 own a Chanel's perfume 1 will be different, unique, special and very confident like Coco would say:

"No elegance is possible without perfume. 
ISSN 2661-2666( Online) International Scientific Journal “Monte" DOI : $\underline{10.33807 / m o n t e .1 .201904125}$ ISSN 2661-264X (Print)

$$
\text { It is the unseen, unforgettable, ultimate accessory" }
$$

\section{References}

1. https://www.google.com/search?biw=1366\&bih=588\&tbm=isch\&sa=1\&ei=7NxWsryL8jawAKNsq34DA\&q=coco+chanel+perfume+quotes\&oq=coco+chanel+perfum e+quotes\&gs I=psy-

ab.3..0.36820.40454.0.40970.7.3.0.4.4.0.158.413.0j3.3.0...0...1c.1.64.psyab..0.7.426...0i67k1.0.PIOgwLTmgkk\#imgrc=pBis2Zy-ciLnXM:

2. https://www.youtube.com/watch?v=ouyXdaNovyQ

3. https://www.biography.com/people/coco-chanel-9244165 